TITLE:

\title{
Femtosecond laser ablation of wide band-gap materials
}

$\operatorname{AUTHOR}(S)$ :

Takayama, Hidetoshi; Maruyama, Toshiro

CITATION:

Takayama, Hidetoshi ...[et al]. Femtosecond laser ablation of wide band-gap materials. Applied Surface Science 2012, 261: 705-707

ISSUE DATE:

2012-11-15

URL:

http://hdl.handle.net/2433/162015

RIGHT:

C 2012 Elsevier B.V.; この論文は出版社版でありません。引用の際には 出版社版をご確認ご利用ください。; This is not the published version. Please cite only the published version. 


\section{Femtosecond laser ablation of wide band-gap materials}

Hidetoshi Takayama and Toshiro Maruyama*

Department of Chemical Engineering, Graduate School of Engineering, Kyoto University, Kyoto 615-8510, Japan

A plasma model proposed by Jiang and Tsai was applied to the experimental results for wide band-gap materials. The model fairly well predicted the laser-fluence dependences of the hole depth and diameter. The analytical threshold fluence represented the pulse-duration dependence very well. However, the model was insufficient to express the crater shape and to predict the threshold fluence. Deviations from the measurements suggest that the effect of ponderomotive force should be taken into account to improve the expression for the crater shape and that the surface energy needed to be additionally taken into account to predict the threshold fluence quantitatively.

Keywords: femtosecond laser, laser ablation, wide band-gap material

*Corresponding author E-mail address: maruyama@ cheme.kyoto-u.ac.jp (T. Maruyama) 


\section{Introduction}

Femtosecond laser ablation of dielectric materials is a new tool for ultraprecise micromachining of small and complex shaped components. It is an active research area which has very significant scientific and engineering merits. In femtosecond laser ablation, the classical heat transfer theories fail to describe the energy and mass transfer in the nanometer length scale and femtosecond time scale, in particular the dissipation of the absorbed energy to lattice and the corresponding material removal process. Several mechanisms for material removal, such as the Coulomb explosion and nonequilibrium thermal vaporization, may coexist and change from one mechanism to another during the removal process. Recently, Jiang and Tsai [1] have proposed the plasma model. The model considered the impact ionization and photoionization to calculate the transient distributions of free electron density and free electron temperature. The highly ionized material under the femtosecond laser ablation was treated as plasma, and the plasma model for metals and doped semiconductors was modified for wide band-gap materials to investigate the time and space dependence of optical properties and laser intensity. They showed that the model predicts the characteristic of the flat-bottom crater shape in the femtosecond laser ablation of dielectrics. However, the materials used as examples to demonstrate and validate the proposed model were restricted to the fused silica [1,2] and barium aluminum borosilicate [3] under limited conditions.

The purpose of this paper is to discuss the applicability of the plasma model to other wide band-gap materials through comparisons with the published experimental threshold fluence and the shape of the crater.

\section{Theoretical Analysis}

Using free electron density as the basic quantity, Jiang and Tsai [1] proposed a new mathematical model to predict the threshold fluence and crater shape of wide band-gap materials at the laser peak intensities on the order of $10^{13}-10^{14} \mathrm{Wcm}^{-2}$. Free 
electron model for the plasma of metals and doped semiconductors was modified to determine the optical properties of the highly ionized wide band-gap materials. Quantum theories were employed to calculate the time and space dependent optical and thermal properties, including the electron heat capacity, electron conductivity, reflectivity, and absorption coefficient. The electron heating and the free electron generation arise in a very short period of time shorter than electron-ion relaxation time, so the Joule heating can be negligible. The important basic equations of the plasma model proposed by Jiang and Tsai [1] is briefly described as follows.

The generation of free electrons that may ultimately lead to optical damage due to strong absorption at the critical density, where the plasma oscillation frequency is equal to the laser frequency, is described by the following well-known equation based on the flux-doubling model and derived from the Fokker-Planck equation.

$$
\frac{\partial n_{e}(t, r, z)}{\partial t}=a_{i} I n_{e}(t, r, z)+\delta_{N} I^{N}
$$

where $t$ is the time; $r$ is the radial distance perpendicular to the Gaussian beam axis; $z$ is the depth from the surface of the bulk material; $n_{\mathrm{e}}(t, r, z)$ is the free electron density; $a_{i}$ is the impact ionization constant; $I$ is the laser intensity inside the bulk material which is a function of $t, r$, and $z ; \delta_{N}$ is the cross-section of $N$-photon absorption. More recently, Jiang and Tsai [4] modified the flux-doubling model by taking into account the electron decay term [5].

Femtosecond irradiation induces a fast energy deposition into the electronic system, temporally decoupled the relaxation to the lattice, simplifying fundamental analyses. The electron heating is governed by the following equation:

$$
c_{e}\left(T, n_{e}\right) n_{e}(t, r, z) \frac{\partial T(t, r, z)}{\partial t}=\alpha_{\mathrm{h}}(t, r, z) I(t, r, z)
$$

where $T$ is the electron temperature, $c_{\mathrm{e}}$ is the electron heat capacity, and $\alpha_{\mathrm{h}}$ is the free electron absorption coefficient.

The original laser beam is assumed to be Gaussian distribution in time and space. 
The laser focus point is assumed to be at $\mathrm{z}=0$. With temporal and spatial dependent optical properties, the laser intensity inside the bulk materials is expressed as

$$
I(t, r, z)=\frac{2 F}{\sqrt{\pi / \ln 2 t_{p}}}(1-R(t, r)) \exp \left(-\frac{r^{2}}{r_{0}^{2}}-(4 \ln 2)\left(\frac{t}{t_{p}}\right)^{2}-\int_{0}^{z} \alpha(t, r, z) \mathrm{dz}\right)
$$

where $F$ is the laser fluence, $R(t, r)$ is the reflectivity at $z=0, \alpha(t, r, z)$ is the absorption coefficient, $r_{0}$ is the radius of the laser beam, $t_{\mathrm{p}}$ is the pulse duration.

It is assumed that the ablation starts when the free electron density reaches the critical density. Once the critical density is created, the originally transparent or semitransparent material becomes opaque, and a large percentage of the absorbed laser energy is deposited in a very thin surface layer within a short period of time, leading to the ablation of the thin layer. Hence, the threshold damage fluence can be assumed as the minimum fluence that just creates the critical density. Similarly, ablation depth is considered to be the maximum depth at which the free electron density is equal to the critical density.

\section{Results and discussion}

The experimental results for the three kinds of materials reported by Guizard et al. [6] and Mero, et al. [7] were used to verify the analysis. Tables 1 and 2 respectively, list the experimental conditions and the characteristic values [8] used in the analysis.

The temporal and spatial changes in free electron density, electron temperature, optical properties, and thermal properties were calculated from the start to the end of the pulse duration by a finite difference method. For $\mathrm{Al}_{2} \mathrm{O}_{3}$, it is not necessary to consider the decay term since Martin et al. [9] reported that they do not observe evidence for self-trapped-exciton formation in $\mathrm{Al}_{2} \mathrm{O}_{3}$. The critical free electron density is $1.74 \times 10^{21} \mathrm{~cm}^{-3}$ for wavelength of $800 \mathrm{~nm}$.

Fig. 1 shows the cross-sectional shapes of the ablation crater. It was analytically obtained by tracing the locations at which the free electron density is equal to the critical density. For $t_{\mathrm{p}}=58$ fs and $F=5.5 \mathrm{~J} / \mathrm{cm}^{2}$, the analysis fairly well represents the 
experimental shape of the crater. For $t_{\mathrm{p}}=1.2 \mathrm{ps}$ and $F=35 \mathrm{~J} / \mathrm{cm}^{2}$, however, the analysis does not represent the experiment, which indicates the phenomenon of double hole formation reported by Ashkenasi et al. [10] for long pulse regime. This phenomennon is attributable to a self-focusing of laser beam spot with nonlinear optical effect by ponderomotive force. The fact that the anharmonicity of bound electron oscillation in a potential perturbed the strong driving laser field is inferred to be related, in a plasma model, to ponderomotive force. The ponderomotive force, which firstly acts upon electrons, ends up with acting upon ions through the effect of the low frequency or direct current components in a characteristic time $\tau_{\mathrm{c}}$, and the self-focusing of laser beam spot by the ponderomotive force can only occur in this time scale. It is noted that the double hole was produced with 1.2 ps pulse but not for 58 fs pulse where the laser intensity is much higher because of the shorter pulse duration. This fact can be explained by the responsibility of ions to ponderomotive force, as follows.

The characteristic time $\tau_{\mathrm{c}}$, by which ponderomotive force move ions, is expressed as

$$
\tau_{\mathrm{c}=} r_{0} / C_{\mathrm{s}}
$$

where $r_{0}$ is the radius of the laser beam. The velocity of sound $C_{\mathrm{s}}$ is given by

$$
C_{\mathrm{s}}=\left(k_{\mathrm{B}} T_{\mathrm{e}} / M\right)^{1 / 2}
$$

where $k_{\mathrm{B}}$ is the Boltzmann constant, $T_{\mathrm{e}}$ the temperature of electron, and $M$ the mass of proton. The velocity of sound for each laser was calculated from the temperature of electron at critical electron density. On the basis of this value, the characteristic time was obtained from Eq. (4), and is listed in Table 3. Judging from the characteristic time, $1.2 \mathrm{ps}$ pulse is enough long but $58 \mathrm{fs}$ pulse is too short for ions to follow ponderomotive force. Thus the difference in behaviour can be explained by the responsibility of ions to ponderomotive force. The plasma model should take into account the ponderomotive force to express the crater shape for $t_{\mathrm{p}}>\tau_{\mathrm{c}}$.

Figs. 2 and 3, respectively, show the hole diameter and hole depth for $\mathrm{Al}_{2} \mathrm{O}_{3}$ at $t_{\mathrm{p}}=$ 
58 fs. The analytical results shown by solid lines well express the laser-fluence dependences of the hole depth and diameter. In Fig. 2 the intercept to the abscissa gives the threshold damage fluence. Fig. 4 shows the threshold fluence as a function of pulse duration. Although the analytical results for $\mathrm{HfO}_{2}$ and $\mathrm{TiO}_{2}$, respectively expressed by solid and dotted line represent the pulse-duration dependence very well, they indicate the smaller values, which are about $0.6-0.8$ of the measurements. The discrepancy from the measurements is inferred to be attributable to the surface energy, which should be additionally taken into account when the depth of the damage approaches the limit to zero, i.e., the surface.

\section{Conclusions}

The plasma model proposed by Jiang and Tsai fairly well predicts the laser-fluence dependences of the hole depth and diameter. The analytical threshold fluence represents the pulse-duration dependence very well. However, the model is insufficient to express the crater shape and to predict the threshold fluence. Deviations from the measurements suggest that the effect of ponderomotive force should be taken into account to improve the expression for the crater shape and that the surface energy needs to be additionally taken into account to predict the threshold fluence quantitatively. 


\section{References}

[1] L. Jiang, H.L. Tsai, Int. J. Heat Mass Transfer 48 (2005) 487.

[2] M. Renzner, J. Kruger, S. Sartania, Z. Cheng, Ch. Spielmann, G. Mourou, W. Kautek, F. Krausz, Phy. Rev. Lett. 80 (1998) 4076.

[3] L. Jiang, H.L. Tsai, J. Appl. Phys. 100 (2006) 023116.

[4] L. Jiang, H.L. Tsai, ASME J, Heat Transfer 128 (2006) 926.

[5] M. Li, S. Menon, J.p. Nibarger, G..N. Gibson, Phy. Rev. Lett. 82 (1999) 2394.

[6] S. Guizard, A. Semerok, J. Gaudin, M. Hashida, P. Martin, F. Quere, Appl. Surf. Sci 186 (2002) 364.

[7] M. Mero, J. Liu, W. Rudolph, D. Ristau, K. Starke, Phy. Rev. B 71 (2005) 115109.

[8] R. Stoian, A. Rosenfeld, D. Ashkenasi, I.V. Hertel, N. M. Bulgakova, E.E.B. Campbell, Phy. Rev. Lett. 88 (2002) 097603.

[9] P. Martin, S. Guizard, Ph. Daguzan, G. Petite, P. D’Oliveira, P. Meynadier, M. Perdrix, Phy. Rev. B 55 (1997) 5799.

[10] D. Ashkenasi, A. Rosenfeld, H. Varel, M. Wähmer, E.E.B. Campbell, Appl. Surf. Sci., 120 (1997) 65. 
Table 1 Experimental conditions for femtosecond laser ablation.

\begin{tabular}{ccccc}
\hline Material & Researchers & $\begin{array}{c}\text { Laser pulse } \\
\text { duration } \\
{[\mathrm{fs}]}\end{array}$ & $\begin{array}{c}\text { Laser } \\
\text { wavelength } \\
{[\mathrm{nm}]}\end{array}$ & $\begin{array}{c}\text { Irradiation } \\
\text { Diameter } \\
{[\mu \mathrm{m}]}\end{array}$ \\
\hline $\mathrm{Al}_{2} \mathrm{O}_{3}$ & Guizard et al.[6] & 58,1200 & 800 & 6 \\
$\mathrm{HfO}_{2}$ & Mero et al.[7] & $25-500$ & 800 & 25 \\
$\mathrm{TiO}_{2}$ & Mero et al.[7] & $25-500$ & 800 & 25 \\
\hline
\end{tabular}

Table 2 Characteristics of materials.

\begin{tabular}{lcccccc}
\hline Material & $\begin{array}{c}\text { Band gap } \\
{[\mathrm{eV}]}\end{array}$ & $\begin{array}{c}a_{\mathrm{i}} \\
{\left[\mathrm{cm}^{2} / \mathrm{J}\right]}\end{array}$ & $\begin{array}{c}\delta_{\mathrm{N}} \\
{\left[\mathrm{cm}^{-3} \mathrm{ps}^{-1}\left(\mathrm{~cm}^{2} / \mathrm{TW}\right)^{\mathrm{N}}\right]}\end{array}$ & $N$ & $U_{\mathrm{i}}$ & $U_{\text {IP }}$ \\
\hline $\mathrm{Al}_{2} \mathrm{O}_{3}$ & 8.8 & 6 & $8 \times 10^{9}$ & 6 & 8.8 & 11.4 \\
$\mathrm{HfO}_{2}$ & 5.1 & 17 & $1.9 \times 10^{16}$ & 5 & 5.1 & 7.5 \\
$\mathrm{TiO}_{2}$ & 3.3 & 5 & $1.8 \times 10^{15}$ & 3 & 3.3 & 4.6 \\
\hline
\end{tabular}

Table 3 Characteristic time $\tau_{\mathrm{c}}$ for the responsibility of ions to ponderomotive force.

\begin{tabular}{cccccc}
\hline Laser & $\begin{array}{c}t_{\mathrm{p}} \\
{[\mathrm{s}]}\end{array}$ & $\begin{array}{c}T_{\mathrm{e}} \\
{\left[\mathrm{J} / \mathrm{cm}^{2}\right]}\end{array}$ & $\begin{array}{c}C_{\mathrm{s}} \\
{[\mathrm{m} / \mathrm{s}]}\end{array}$ & $\begin{array}{c}\tau_{\mathrm{c}} \\
{[\mathrm{s}]}\end{array}$ \\
\hline Fig.1(a) & $58 \times 10^{-12}$ & 5.5 & $3.2 \times 10^{5}$ & $5.1 \times 10^{4}$ & $1.18 \times 10^{-10}$ \\
Fig.1(b) & $1.2 \times 10^{-9}$ & 35 & $6.1 \times 10^{5}$ & $7.0 \times 10^{4}$ & $8.5 \times 10^{-11}$ \\
\hline
\end{tabular}


Figure caption

Fig. 1. Cross-sectional shape of the crater for $\mathrm{Al}_{2} \mathrm{O}_{3}$ at (a) $t_{\mathrm{p}}=58$ fs and $F=5.5 \mathrm{~J} / \mathrm{cm}^{2}$ and (b) $t_{\mathrm{p}}=1.2 \mathrm{ps}$ and $F=35 \mathrm{~J} / \mathrm{cm}^{2}$.

Fig. 2. Hole diameter for $\mathrm{Al}_{2} \mathrm{O}_{3}$ at $t_{\mathrm{p}}=58$ fs as a function of laser fluence.

Fig. 3. Hole depth for $\mathrm{Al}_{2} \mathrm{O}_{3}$ at $t_{\mathrm{p}}=58 \mathrm{fs}$ as a function of laser fluence.

Fig. 4. Threshold fluence for $\mathrm{HfO}_{2}$ and $\mathrm{TiO}_{2}$ as a function of pulse duration. Analytical results for $\mathrm{HfO}_{2}$ and $\mathrm{TiO}_{2}$ are expressed by solid and dotted line, respectively. 


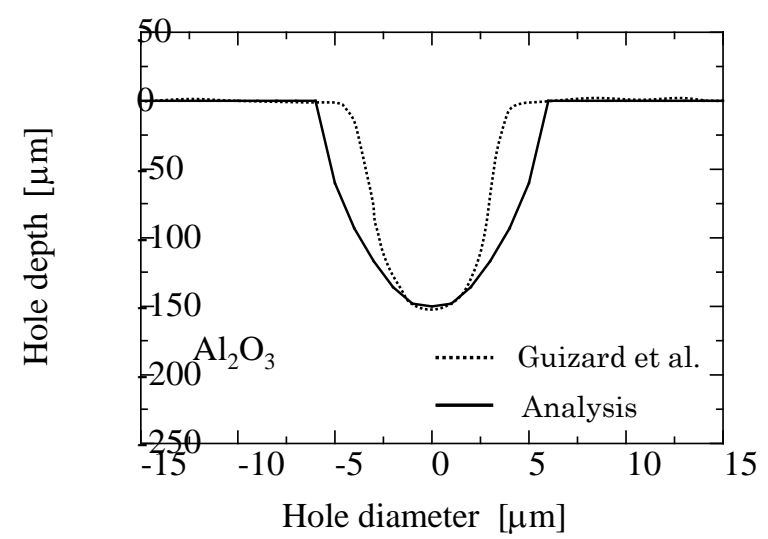

Fig.1(a) 


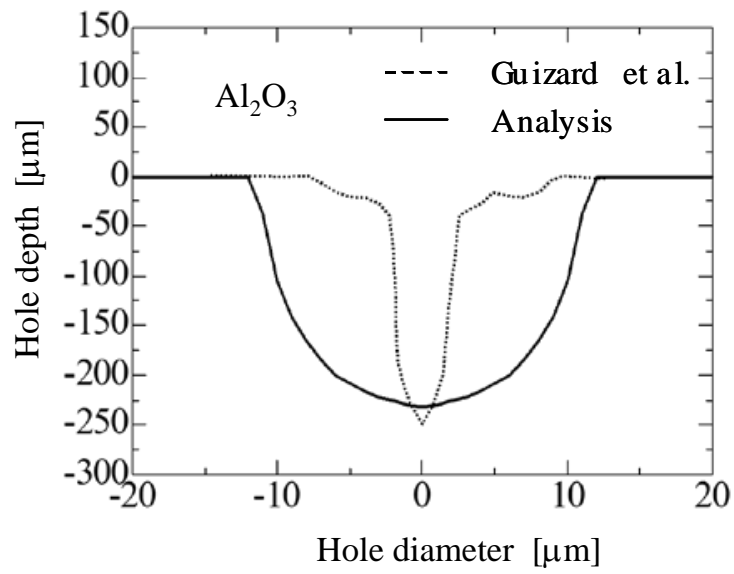

Fig.1(b) 


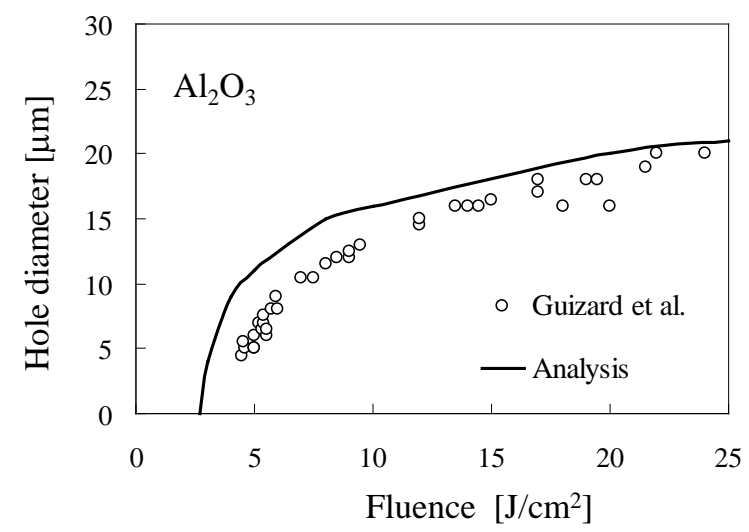

Fig.2 


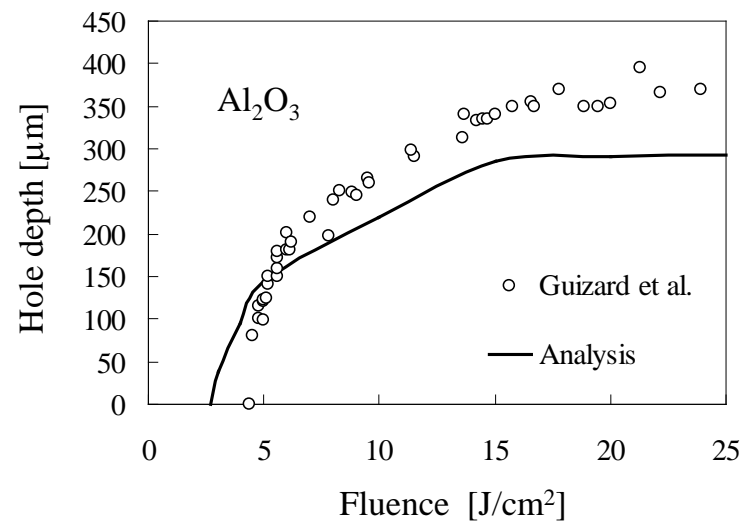

Fig.3 


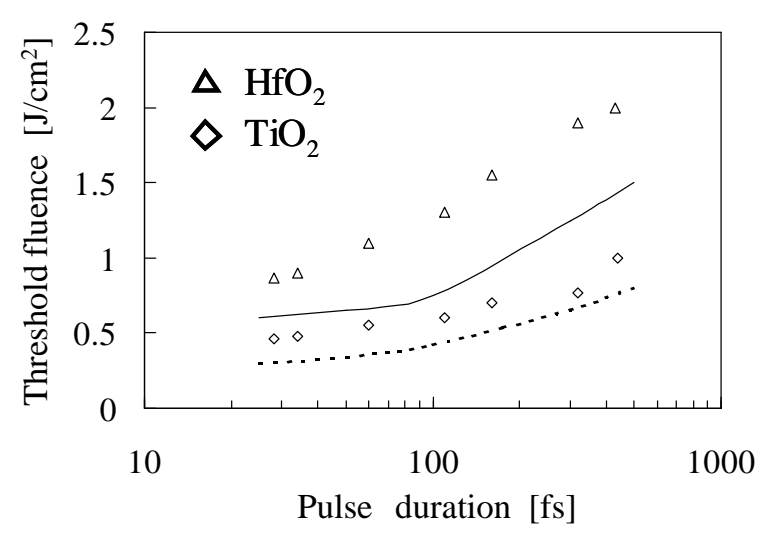

Fig.4 